\title{
New Botryosphaeriales on native red milkwood (Mimusops caffra)
}

\author{
Fahimeh Jami $^{1, *}$, Seonju Marincowitz ${ }^{1}$, Bernard Slippers ${ }^{1}$, Michael J. Wingfield ${ }^{1}$ \\ ${ }^{1}$ Department of Biochemistry, Genetics \& Microbiology, Forestry \& Agricultural Biotechnology Institute (FABI), \\ University of Pretoria, Pretoria, South Africa \\ *E-mail: fahimeh.jami@fabi.up.ac.za (for correspondence)
}

\begin{abstract}
Fungi in the Botryosphaeriales (Ascomycetes) are common endophytes in woody plants with a wide global distribution and in some cases they are important tree pathogens. The aim of this study was to consider the possible cause of die-back on native coastal red milkwood (Mimusops caffra) trees growing on the east coast of South Africa. Samples were taken from symptomatic tissue and isolations were made. The resulting isolates were identified based on DNA sequence data from the rDNA-ITS, translation elongation factor $1-\alpha$ and $\beta$-tubulin loci. Two new species in the Botryosphaeriales, namely Neofusicoccum variabile sp. nov. and Pseudofusicoccum africanum sp. nov., were found together with an isolate of N. mangroviorum. Neofusicoccum mangroviorum produced significantly longer lesions than the other two species and the control inoculations in pathogenicity tests and it appears to be the cause of the die-back disease.
\end{abstract}

Keywords Botryosphaeriales, milkwood, pathogenic, native trees, taxonomy

\section{Introduction}

The Botryosphaeriales (Dothideomycetes) includes nine families, 32 genera and 279 species (Slippers et al. 2017), and is one of the most widespread and cosmopolitan groups of fungi. They 
typically occur as endophytes of woody plants and include important latent pathogens (Slippers and Wingfield, 2007). Species of Botryosphaeriales cause diseases when their hosts are under stress (Slippers and Wingfield, 2007), the situation is increasingly common in many parts of the world affected by climate change (Desprez-Loustau et al. 2006; Sturrock et al. 2011). Although the number of studies on Botryosphaeriales has increased substantially in recent decades, much has yet to be learned regarding their host ranges, distribution and biology (Crous et al. 2016; Marsberg et al. 2017).

Species in the Botryosphaeriales have been relatively well-studied in South Africa (Jami et al. 2017). These fungi occur widely in the country and they have been found on all tree species that have been sampled for them. In this regard, 62 species are known from 66 hosts, of which 37 are known only from native trees (Jami et al. 2017). Despite relatively extensive sampling that has been undertaken in South Africa for the Botryosphaeriales, there are many woody plants that have not yet been considered in this highly bio-diverse region of the world.

Mimusops caffra (Sapotaceae), commonly known as coastal red milkwood, is an important tree in South Africa from an ecological standpoint. For example, it plays important ecological roles such as stabilising coastal forests sands, the fruits can be used for various food products and some plant parts are used in traditional medicine (www.plantzafrica.com). Virtually nothing is known regarding the diseases of red milkwood, and this is despite the fact that it is a protected tree (South African Government Gazette, 2013) and threatened by unsustainable utilization practices.

In recent years, there have been numerous informal observations of die-back on $M$. caffra trees (Wingfield, personal observations). The aim of this study was thus to identify the possible cause of these die-back symptoms from samples collected on the east coast of South Africa. 


\section{Materials and methods}

\section{Collection of samples and isolations}

Branch samples were collected from die-back symptoms (Fig. 1) in the Eastern Cape Province, between the towns of Cintsa and Kei Mouth during December of 2011 and 2015. Ten trees were randomly chosen for sampling in each year. The diseased branches (Fig. 1) were placed in paper bags and transferred to the laboratory for further study. Fruiting structures observed on the branches were placed under a dissecting microscope and conidia found emerging from them. These conidia were lifted from the structures using a sterile needle and transferred to malt extract agar (MEA: $2 \%$ Biolab malt extract, $2 \%$ Difco agar) supplemented with streptomycin (400 mg/L). Specimens from this study were lodged in South African National Collection of Fungi (PREM),

Roodeplaat, Pretoria, South Africa. Living cultures were preserved in the collection (CMW) of the Forestry and Agricultural Biotechnology Institute, University of Pretoria, Pretoria, South Africa. A subset of cultures representing novel taxa were lodged at the culture collection (CBS) of Westerdijk Fungal Biodiversity Institute, Utrecht, the Netherlands and the South African National Collection of Fungi (PPRI), Roodeplaat, South Africa. 

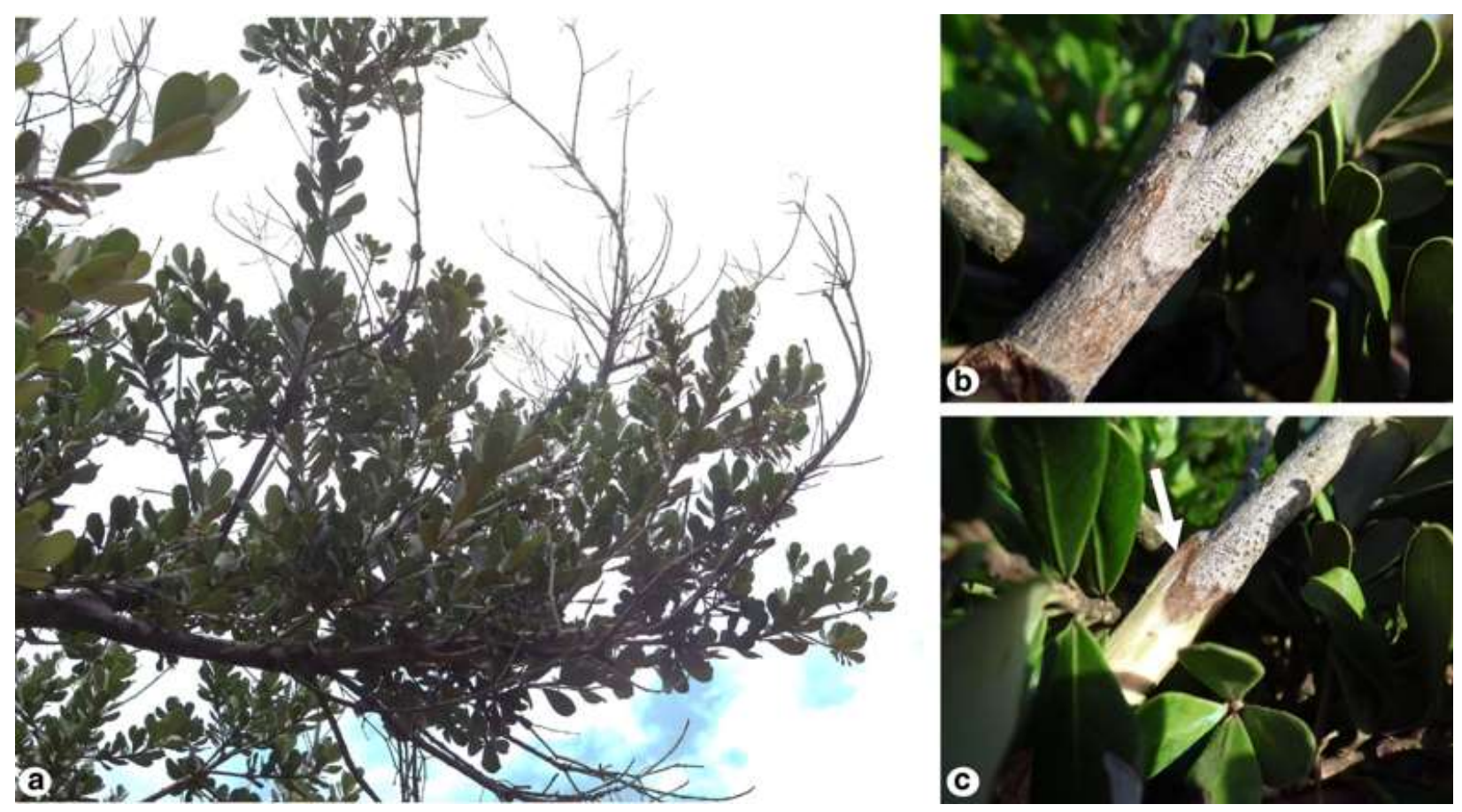

Figure 1. A. Mimusops caffra tree with die-back branches. B. Die-back branch. C. Discolouration under the bark (arrow).

\section{DNA sequencing}

DNA was extracted using PrepMan ${ }^{\circledR}$ Ultra kit (Applied Biosystems) from mycelium of 5-dayold pure cultures. DNA sequences were generated for the internal transcribed spacer region of the ribosomal RNA (rRNA) operon amplified with primers ITS-1F (Gardes and Bruns 1993) and ITS4R (White et al. 1990) and the translation elongation factor 1- $\alpha$ (TEF1- $\alpha$ ) gene amplified with primers EF1-728F and EF1-986R (Carbone and Kohn, 1999). To clarify the position of species related to unidentifed Neofusicoccum, we also included sequence data from the $\beta$-tubulin (TUB2) gene amplified with primers BT2a and BT2b (Glass and Donaldson, 1995) for a selected group of isolates. The conditions for the PCRs were the same as those described in Jami et al. (2012). 
The phylogenetic analyses for all the datasets were performed using Maximum Likelihood (ML). The best nucleotide substitution models for each dataset were found separately with Modeltest 3.7 (Posada and Buckley, 2004). The model for GTR was chosen for the combined datasets of ITS, TEF 1- $\alpha$ and TUB2. The ML analyses were performed in PAUP $4.0 \mathrm{~b} 10$ and confidence levels were determined with 1000 bootstrap replications. The consensus trees were constructed in MEGA version 7 and posterior probabilities were assigned to branches after a $60 \%$ majority rule.

\section{Morphological characteristics}

Fruiting structures containing spores on the host substrate were opened using a scalpel. Fungal structures were moistened, picked up with a sterile syringe needle and mounted on microscope slides in water that was later replaced with $85 \%$ lactic acid in which all the measurements and images were done. Up to fifty measurements were made for spores and other morphologically characteristic structures where these were available. To prepare vertical sections of the fungal structures embedded in the substrate, the specimens bearing fungal structures were cut into small pieces and soaked in sterile water overnight. The saturated pieces were mounted in Tissue Freezing Medium ${ }^{\circledR}$ (Leica, Germany) and cut into sections of 10-12 $\mu \mathrm{m}$ thickness using Leica Cryomicrotome (Leica, Germany). The sections were mounted on microscope slides in $85 \%$ lactic acid for further observation. Observations were made using Nikon Eclipse Ni compound and SMZ 18 stereo microscopes (Nikon, Japan). Images were captured with a Nikon DS-Ri camera and with the imaging software NIS-Elements BR.

Growth of isolates in culture was studied in the dark at temperatures ranging from $10^{\circ} \mathrm{C}$ to 35 ${ }^{\circ} \mathrm{C}$ at $5{ }^{\circ} \mathrm{C}$ intervals. An agar block containing actively growing hyphae was placed at the centre of $90 \mathrm{~mm}$ Petri dishes containing $2 \%$ MEA. Three replicate plates were used for each isolate per temperature. Cultures were allowed to grow until the fastest growing isolate reached the edge of a 
Petri dish at which point the experiment was terminated and two measurements perpendicular to each other of colony diameter were made. The averages of the colony diameters were then computed. Colony colours were assigned using the designations of Rayner (1970).

\section{Pathogenicity tests}

Two isolates of each of the Botryosphaeriales species that were identified based on phylogenetic analyses were randomly selected for inoculations. Branches of $M$. caffra were approximately 1$1.5 \mathrm{~cm}$ in diameter were cut from healthy trees and their ends were sealed with paraffin wax immediately after cutting. Each of the isolates was inoculated at the centers of the branches by removing a $6 \mathrm{~mm}$ disc of bark using a cork borer and replacing this with a disc of similar size taken from the edge of an actively growing culture. In the case of the controls, the wounds were replaced with a disc of MEA from a non-inoculated plate. The inoculation wounds were wrapped tightly with Parafilm to avoid desiccation of the inoculation sites. Inoculated branches were maintained at room temperature for five weeks. The inoculation sites were then exposed and lesion lengths were measured. Variation in the extent of the lesions was analyzed through a two-way analysis of variance using $\mathrm{R}$ version 3.2.4. Small pieces of tissue from the lesions including the inoculation points were cut, surface-disinfested with $5 \%$ hydrogen peroxide for two minutes, and rinsed three times in sterile water. The prepared tissue samples were plated onto $2 \%$ MEA and incubated at 24 ${ }^{\circ} \mathrm{C}$ for seven days after which isolates were identified based on morphological characters and ITS sequences. 


\section{Results}

Isolates and DNA sequence analyses

A total of 12 isolates were obtained from die-back symptoms on 20 sampled trees. The sequence datasets for the ITS, TEF1- $\alpha$ and TUB2 were analysed individually and in combination. The ITS sequence dataset contained 556 characters, TEF1- $\alpha$ dataset contained 314 characters, TUB2 dataset contained 354 characters and combined dataset contained 1224 characters (TreeBase Accession No. S21688) (Table 1).

Table 1. The Botryosphaeriales isolates from Mimusops caffra (Haga Haga, Eastern Cape, South Africa) of this study used in the phylogenetic analyses. Type isolates are indicated in bold.

\begin{tabular}{|c|c|c|c|c|}
\hline \multirow{2}{*}{ Isolate No. } & \multirow{2}{*}{ Identity } & \multicolumn{3}{|c|}{ GenBank } \\
\hline & & ITS & TEF1- $\alpha$ & TUB2 \\
\hline CMW 37739' $^{\mathrm{T}}$ & Neofusicoccum variabile & MH558608 & - & MH569153 \\
\hline CMW 37742 & “ & MH558609 & MH576585 & MH569154 \\
\hline CMW 37745 & “ & MH558610 & MH576586 & MH569155 \\
\hline CMW 37747 & “ & MH558611 & MH576587 & MH569156 \\
\hline CMW 37748 & “ & MH558612 & MH576588 & MH569157 \\
\hline CMW 48031 & N. mangroviorum & MH558613 & - & - \\
\hline CMW $48028^{\mathrm{T}}$ & Pseudofusicoccum africanum & MH558614 & MH576590 & - \\
\hline CMW 48025 & “ & MH558615 & MH576589 & - \\
\hline CMW 48027 & “ & MH558616 & MH576591 & - \\
\hline CMW 48029 & “ & MH558617 & MH576592 & - \\
\hline CMW 48030 & “ & MH558618 & MH576593 & - \\
\hline CMW 48035 & “ & MH558619 & MH576594 & - \\
\hline
\end{tabular}




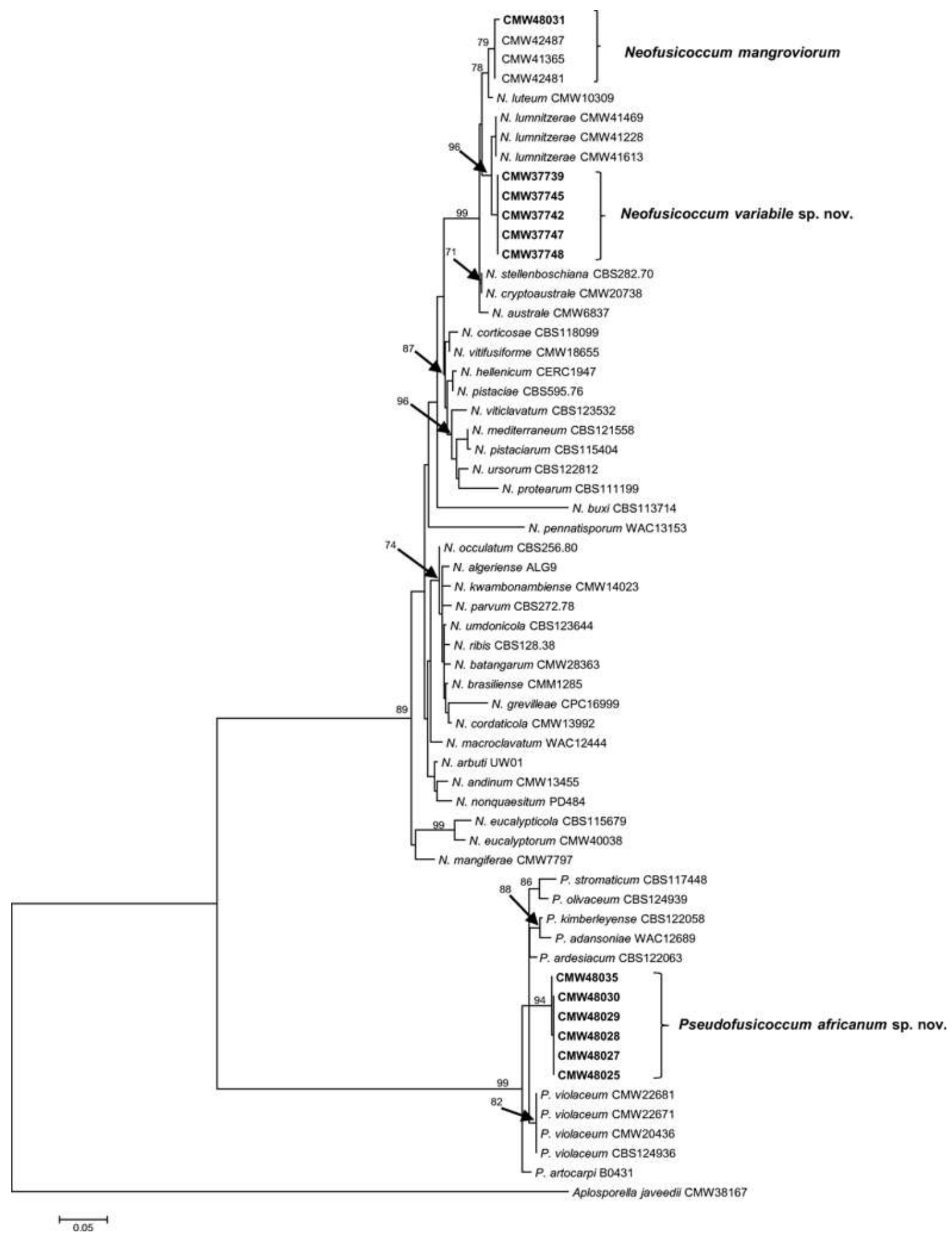

Figure 2. Maximum Likelihood (ML) tree of the combined data set of ITS ribosomal DNA and TEF1- $\alpha$ gene region sequences. Bootstrap values above $75 \%$ are given at the nodes. The tree was rooted to Aplosporella javeedii (CMW 38167). Isolates of this study are indicated as bold. 


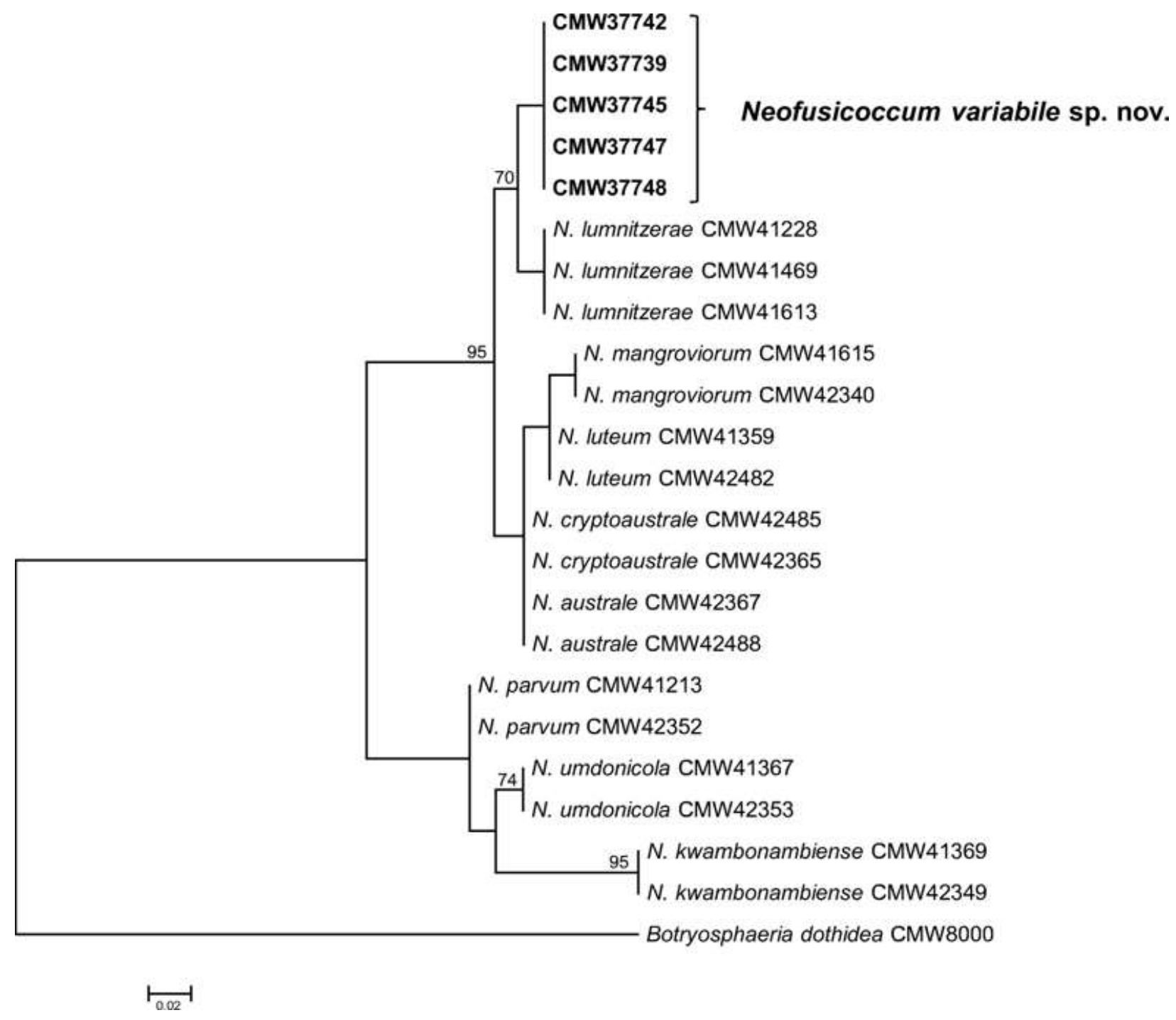

Figure 3. Maximum Likelihood (ML) tree of TEF1- $\alpha$ and $\beta$-tubulin loci. Bootstrap values above $75 \%$ are given at the nodes. The tree was rooted to Botryosphaeria dothidea (CMW 8000). Isolates of this study are indicated as bold.

Three clades were identified in all the analyses and these represented Neofusicoccum mangroviorum and two unidentified groups in the clades accommodating Neofusicoccum and Pseudofusicoccum respectively (Fig. 2). The ITS sequences of unidentified Neofusicoccum isolates were identical to the ITS sequences of $N$. lumnitzerae and they clustered together in the ITS tree. However, these isolates were clustered as a distinct clade in the combined datasets of 
TEF1- $\alpha$ and TUB2 (Fig. 3), and differed from N. lumnitzerae by unique fixed alleles in TEF1- $\alpha$ (5 bp) and TUB2 (2 bp) (Table 2). The topology of the trees emerging from the ML was similar for TEF1- $\alpha$ and TUB2 loci, as well as in the combined analyses, with regards to the clades representing species isolated in this study. The unidentified Pseudofusicoccum isolates clustered as a sister clade to $P$. violaceum and they differed from that species by one bp in ITS and $13 \mathrm{bp}$ in TEF1- $\alpha$ (Table 3).

Table 2. Polymorphic nucleotides from sequence data of the $T E F 1-\alpha$ and $T U B 2$ for isolates in Neofusicoccum variabile sp. nov. and N. lumnitzerae.

\begin{tabular}{|c|c|c|c|c|c|c|c|c|}
\hline \multirow[b]{2}{*}{ Identity } & \multicolumn{6}{|c|}{ TEF1- $\alpha$} & \multicolumn{2}{|c|}{ TUB2 } \\
\hline & Isolate no. & 116 & 200 & 250 & 282 & 294 & 22 & 280 \\
\hline \multirow[t]{2}{*}{ Neofusicoccum lumnitzerae } & CMW 41613 & $\mathrm{C}$ & $\mathrm{C}$ & $\mathrm{T}$ & G & $\mathrm{T}$ & $\mathrm{C}$ & $\mathrm{C}$ \\
\hline & CMW 41228 & 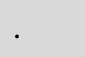 & . & . & . & . & . & . \\
\hline “ & CMW 41469 & & . & . & . & . & . & . \\
\hline \multirow{2}{*}{$\begin{array}{l}\text { Neofusicoccum variabile sp. } \\
\text { nov. }\end{array}$} & CMW $37739^{\mathrm{T}}$ & $\mathbf{A}$ & $\mathbf{T}$ & $\mathbf{C}$ & $\mathbf{A}$ & $\mathbf{C}$ & $\mathbf{T}$ & $\mathbf{A}$ \\
\hline & CMW 37742 & & & & . & . & . & . \\
\hline " & CMW 37745 & & . & . & . & . & . & . \\
\hline " & CMW 37747 & & . & . & . & . & . & . \\
\hline “ & CMW 37748 & & & & . & . & . & . \\
\hline
\end{tabular}


Table 3. Polymorphic nucleotides from sequence data of the ITS and TEF1- $\alpha$ for isolates in Pseudofusicoccum africanum sp. nov. and $P$. violaceum.

\begin{tabular}{|c|c|c|c|c|c|c|c|c|c|c|c|c|c|c|c|}
\hline & & ITS & & & & & & & & & & & & & \\
\hline \multirow{2}{*}{$\begin{array}{l}\text { Identity } \\
\text { Pseudofusicoccum } \\
\text { violaceum }\end{array}$} & Isolate no. & 136 & 15 & 34 & 64 & 78 & 92 & 102 & 143 & 169 & 211 & 212 & 218 & 261 & 323 \\
\hline & CBS 124936 & $\mathrm{~T}$ & A & $\mathrm{C}$ & A & $\mathrm{T}$ & $\mathrm{T}$ & $\mathrm{C}$ & $\mathrm{T}$ & $\mathrm{C}$ & $\mathrm{T}$ & G & $\mathrm{C}$ & G & $\mathrm{C}$ \\
\hline “ & CMW 22671 & . & . & . & . & . & . & . & & . & . & . & . & . & . \\
\hline “ & CMW 20436 & . & . & . & . & . & . & . & . & . & . & . & . & . & . \\
\hline “ & CMW 22681 & . & . & . & . & . & . & . & . & . & . & . & . & . & . \\
\hline \multirow{2}{*}{$\begin{array}{l}\text { Pseudofusicoccum } \\
\text { africanum sp. nov. }\end{array}$} & CMW 48025 & C & G & $\mathbf{T}$ & G & $\mathbf{G}$ & $\mathbf{T}$ & $\mathbf{T}$ & C & $\mathbf{T}$ & C & $\mathbf{A}$ & A & A & $\mathbf{T}$ \\
\hline & CMW 48027 & . & . & . & . & . & . & . & & . & . & . & . & . & . \\
\hline “ & CMW $48028^{\mathrm{T}}$ & . & . & . & . & . & . & . & . & . & . & . & . & . & . \\
\hline " & CMW 48029 & . & . & . & . & . & . & . & . & . & . & . & . & . & . \\
\hline “ & CMW 48030 & . & . & . & . & . & . & . & . & . & . & . & . & . & . \\
\hline “ & CMW 48035 & . & . & . & . & . & . & . & & . & . & . & . & . & . \\
\hline
\end{tabular}




\section{Morphological characteristics}

The isolates in the groups corresponding to both Neofusicoccum and Pseudofusicoccum had light to dark grey colonies. The Neofusicoccum isolates grew more rapidly and with abundant aerial hyphae that reached the Petri dish lids. Neofusicoccum cultures produced large hyaline fusoid to cylindrical conidia. Pseudofusicoccum cultures had dense hyphae with irregular edges. Pseudofusicoccum isolates produced aseptate hyaline or brown conidia that were cylindrical with round ends.

\section{Taxonomy}

Two unknown taxa emerged from the phylogenetic analyses and are described here follows:

\section{Neofusicoccum variabile Marinc., Jami \& M.J. Wingf. sp. nov. MB 823176. Fig. 4.}

Etymology: Name refers to the variability in the shape of the conidia.

Ascostromata gregarious, immersed in the substrate, subperidermal, uni- or multiloculate, ostiolate, 165-260 $\mu \mathrm{m}$ long, 240-565 $\mu \mathrm{m}$ wide. Stromata composed of dark-brown, thick-walled cells of textura globulosa. Ascomata ellipsoidal to subglobose, 110-175 $\mu \mathrm{m}$ long excluding a neck, 160-270 $\mu \mathrm{m}$ wide, with short neck reaching the surface of epidermis, $60-115 \mu \mathrm{m}$ long. Ascomatal walls pseudoparenchymatous, 9-24 $\mu \mathrm{m}$ thick, outer tier composed of 3-4 layers of thick-walled, dark brown and compressed cells, inner tier composed of 2-3 layers of hyaline, thin-walled and compressed cells. Asci dispersed among pseudoparaphyses, bitunicate, clavate, 80-140 $\mu \mathrm{m}$ long, 17.5-22 $\mu \mathrm{m}$ wide. Ascospores hyaline, 1-celled, fusoid to ellipsoid, smooth, 17.5-22.5 $\times 8-11 \mu \mathrm{m}$ (avg. $19.6 \times 9.5 \mu \mathrm{m}$ ). 

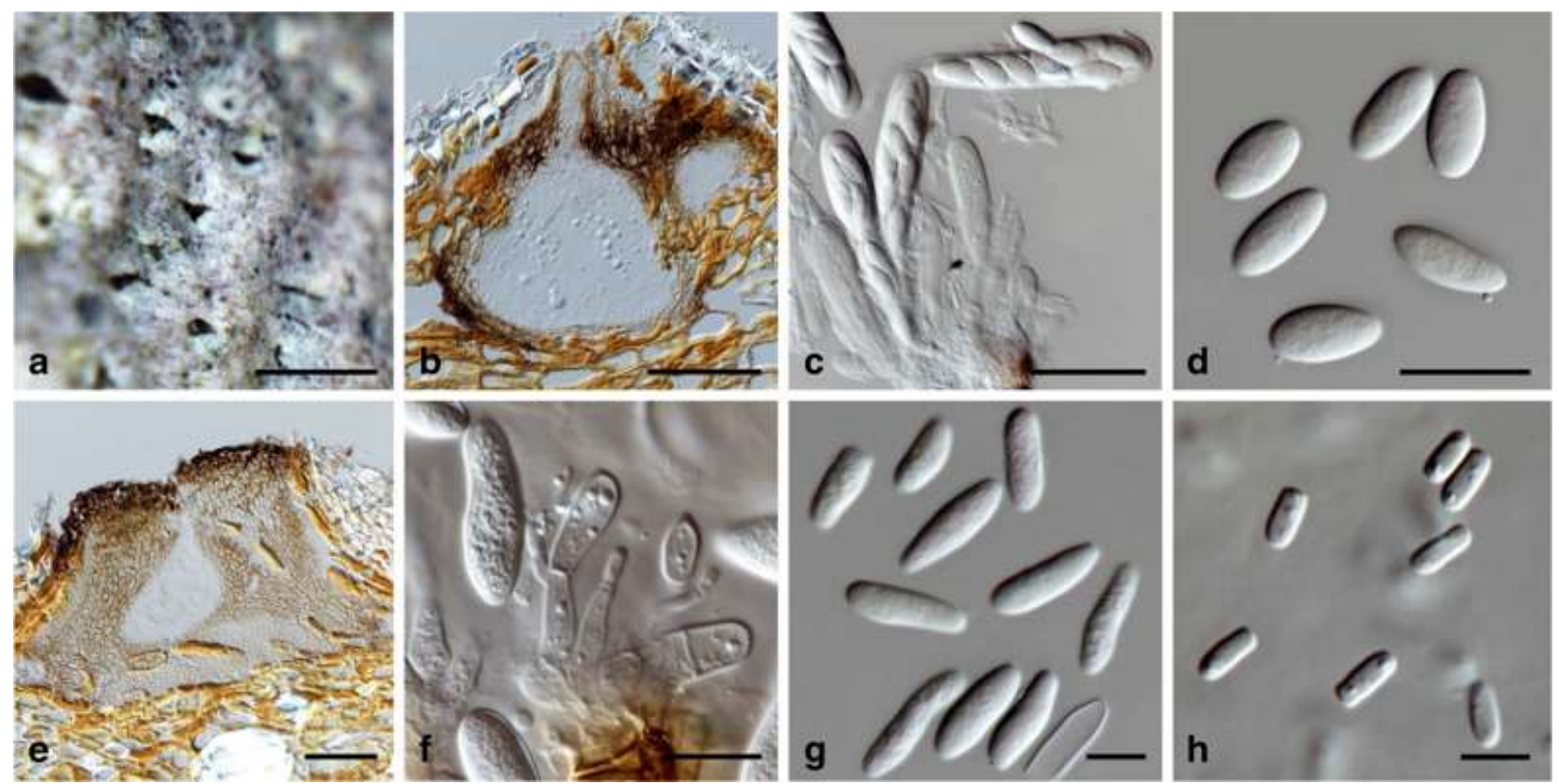

Figure 4. Microscopic images of Neofusicoccum variabile (holotype PREM 62174). A. Fruiting structures in the substrate. B. Vertical section of ascostromata. C. Asci. D. Ascospores. E. Vertical section of Conidioma (paratype PREM 62176). F. Conidiogenous cells. G. Conidia. H. Spermatia. Scale bars: A=500 $\mu \mathrm{m} ; \mathrm{B}, \mathrm{E}=100 \mu \mathrm{m} ; \mathrm{C}=50 \mu \mathrm{m}$; $\mathrm{D}=25 \mu \mathrm{m} ; \mathrm{F}, \mathrm{G}=10 \mu \mathrm{m} \mathrm{H}=5 \mu \mathrm{m}$.

Conidiomata immersed in the substrate becoming erumpent, 185-260 $\mu \mathrm{m}$ long, 325-545 $\mu \mathrm{m}$ wide, multiloculate, locules 125-180 $\mu \mathrm{m}$ long, 55-130 $\mu \mathrm{m}$ wide. Conidiophores arising from peridial wall, hyaline, septate, often branched. Conidiogenous cells blastic, cylindrical to clavate, tapering towards apex, 4-13.5 $\mu \mathrm{m}$ long, 1.5-4 $\mu \mathrm{m}$ wide. Conidia hyaline, shape in range from fusoid to cylindrical with round ends, often truncate base, straight or curved, 1-celled, 14.5-24.5 $\times 4.5-8 \mu \mathrm{m}($ avg. $20 \times 6.4 \mu \mathrm{m})$. Spermatia hyaline, oblong with rounded apex, 1-celled, 3.5-6 $\times$ 1.5-2.5 $\mu \mathrm{m}($ avg. $4.3 \times 1.9 \mu \mathrm{m})$.

Culture characteristics on $2 \%$ MEA in the dark for $7 \mathrm{~d}$, showing optimum growth at $25{ }^{\circ} \mathrm{C}$ reaching $78 \mathrm{~mm}$, followed by at $20{ }^{\circ} \mathrm{C}$ reaching $53.7 \mathrm{~mm}$, at $30{ }^{\circ} \mathrm{C}$ reaching $46.2 \mathrm{~mm}$, at $15{ }^{\circ} \mathrm{C}$ 
reaching $25 \mathrm{~mm}$, at $10^{\circ} \mathrm{C}$ reaching $10.3 \mathrm{~mm}$, and no growth at $35^{\circ} \mathrm{C}$. Colony morphology varying in different temperature, at $25^{\circ} \mathrm{C}$ growing circular with undulate to lobate edges, aerial mycelium fluffy to cottony, dense, above outer-half colony mostly aerial, buff-greenish olivaceous, innerhalf colony submerged, dark mouse grey, reverse inner-half black becoming olivaceous towards the outer.

Specimens examined: SouTH AFRICA, Eastern Cape province, Haga Haga, Dec 2011, M. J. Wingfield, symptomatic twigs of Mimusops caffra (coastal red milkwood), holotype PREM 62174 = FABI-H 3888, ex-holotype CBS 143480 = CMW 37739, paratype PREM 62176 = FABI-H 3891, living culture CBS 143482 = CMW 37747. Additional specimens examined: PREM 62175 = FABI-H 3889, living culture CBS 143481 = CMW 37745, other cultures CMW 37742, CMW 37748.

Notes: No asexual structures were found on the twigs on which sexual structures were observed. Morphological characteristics of the sexual and asexual states are based on specimens FABI-H 3891 and CMW 37747, respectively. Neofusicoccum variabile differs from its closest phylogenetic relative, $N$. lumnitzerae, by unique fixed alleles in TEF1- $\alpha$ and TUB2 loci based on alignments of the separate loci deposited in TreeBASE as study S21688 (Table 2).

Pseudofusicoccum africanum Marinc., Jami \& M.J. Wingf. sp. nov. MB 823177. Fig. 5.

Etymology: Name refers to the continent where strains of this fungus were collected. 

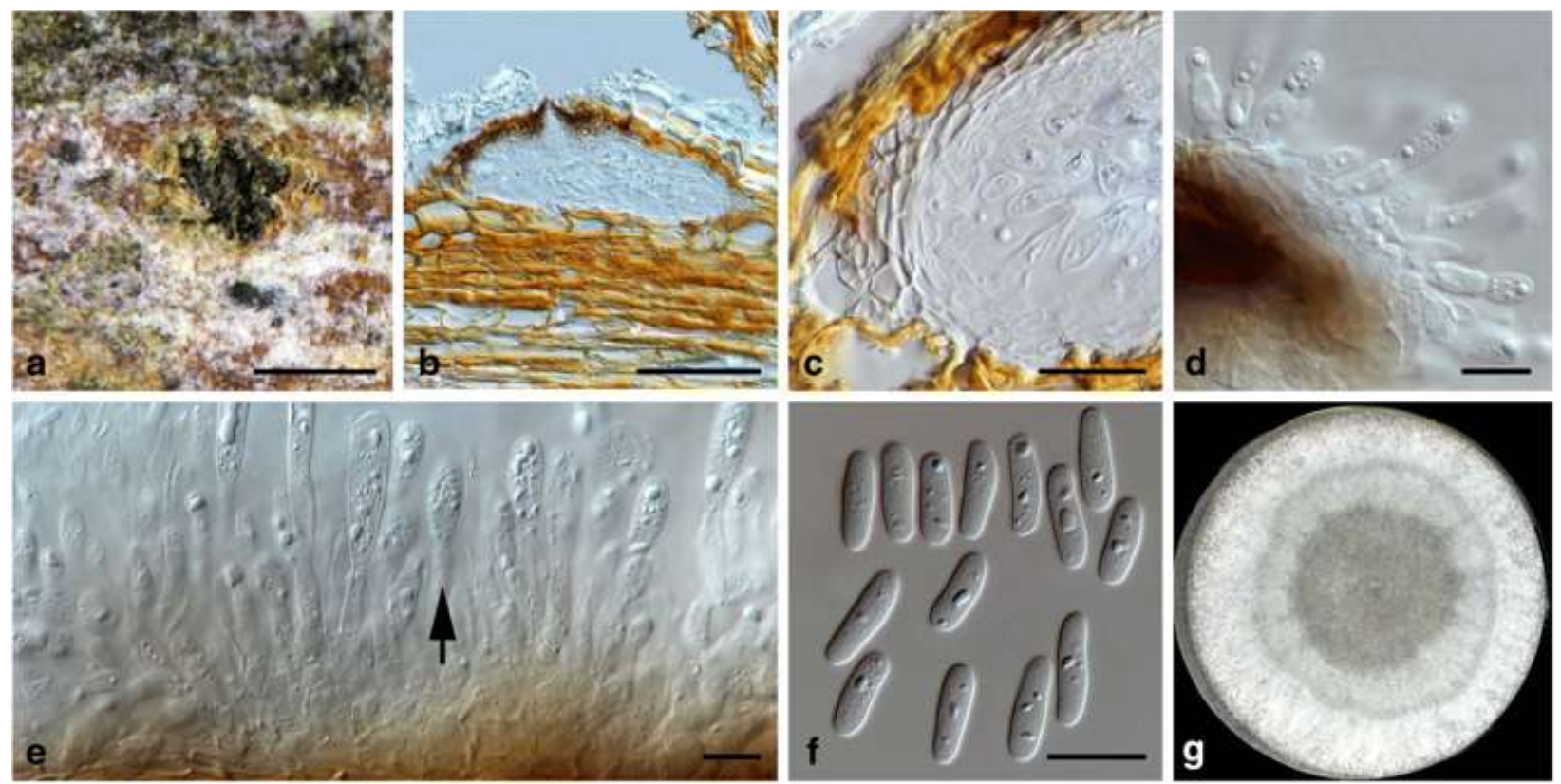

Figure 5. Microscopic images of Pseudofusicoccum africanum (holotype PREM 62172, ex-holotype, PREM 62171).

A. Fruiting structure in the substrate. B. Vertical section of conidioma. C. Conidiomatal wall. D. E. Conidiogenous cells showing annellations (arrow). F. Conidia. G. Culture grown at optimum temperature $\left(30^{\circ} \mathrm{C}\right)$ on $2 \% \mathrm{MEA}$ in the dark for $7 \mathrm{~d}$. Scale bars: $\mathrm{A}=500 \mu \mathrm{m} ; \mathrm{B}=100 \mu \mathrm{m} ; \mathrm{C}, \mathrm{F}=25 \mu \mathrm{m} ; \mathrm{D}, \mathrm{E}=10 \mu \mathrm{m}$.

Conidiomata dispersed in the substrate, immersed, subperidermal, ostiolate, with the tip of ostiole reaching the surface of epidermis, becoming erumpent, gregarious, uni- to multiloculate, ellipsoidal, 70-185 $\mu \mathrm{m}$ long, 160-280 $\mu \mathrm{m}$ wide. Conidiomatal walls pseudoparenchymatous, 4.5$17.5 \mu \mathrm{m}$ thickness, consisted of 1-2 tiers, outer tier composed of a few dark brown, thick-walled, compressed cells, especially around the ostiole and the upper half of conidioma, inner tier composed of layers of hyaline, thick-walled, highly compressed cells, especially at the lower half and the base of conidioma. Conidiophores arising from the wall, frequently reduced to conidiogenous cells. Conidiogenous cells blastic, showing percurrent growth, hyaline, cylindrical 
to clavate, 5.5-18.5 × 2.5-6 $\mu \mathrm{m}$. Conidia hyaline, 1-celled, smooth, cylindrical with round ends, straight or curved, $20.5-34 \times 5.5-8 \mu \mathrm{m}($ avg. $26.7 \times 6.6 \mu \mathrm{m})$.

Culture characteristics on $2 \%$ MEA in the dark for $7 \mathrm{~d}$, showing optimum growth at $30{ }^{\circ} \mathrm{C}$ reaching $85 \mathrm{~mm}$, followed by at $25{ }^{\circ} \mathrm{C}$ reaching $53.3 \mathrm{~mm}$, at $20^{\circ} \mathrm{C}$ reaching $25.2 \mathrm{~mm}$, at $35{ }^{\circ} \mathrm{C}$ reaching $17.2 \mathrm{~mm}$, at $15^{\circ} \mathrm{C}$ reaching $9.7 \mathrm{~mm}$, and no growth at $10^{\circ} \mathrm{C}$. Colony morphology varying in different temperature, becoming darker with higher temperature, at $30{ }^{\circ} \mathrm{C}$ growing circular with smooth margin, aerial hyphae fluffy, medium dense, above and reverse iron grey inner becoming olivaceous buff towards the outer.

Specimens examined: SouTH AFRICA, Eastern Cape province, Haga Haga, Dec 2015, M. J. Wingfield, twigs of Mimusops caffra (coastal red milkwood), PREM 62172 = FABI-H 4077 holotype, ex-holotype CMW 48028 = PPRI xxxx. Additional specimens examined: PREM 62171 = FABI-H 4078, living culture CMW 48027, PREM 62173 = FABI-H 4074, living culture CMW 48030, other cultures CMW 48025, CMW 48026, CMW 48029, CMW 48035.

Note: Pseudofusicoccum africanum differs from its closest known phylogenetic neighbour, $P$. violaceum, by unique fixed alleles in ITS and TEF $1-\alpha$ loci based on alignments of the separate loci deposited in TreeBASE as study S21688 (Table 3).

\section{Pathogenicity tests}

The six isolates representing the three species emerging from this study all produced lesions in the cambium of inoculated $M$. caffra branches within five weeks. In contrast, there was no lesion development for the control inoculations (Fig. 6). Statistical analyses showed that lesion length for the three species of fungi was relatively consistent between replications, but varied considerably between species. The longest lesions were produced by $N$. mangroviorum $(\mathrm{X}=69.5 \mathrm{~mm})$, followed 

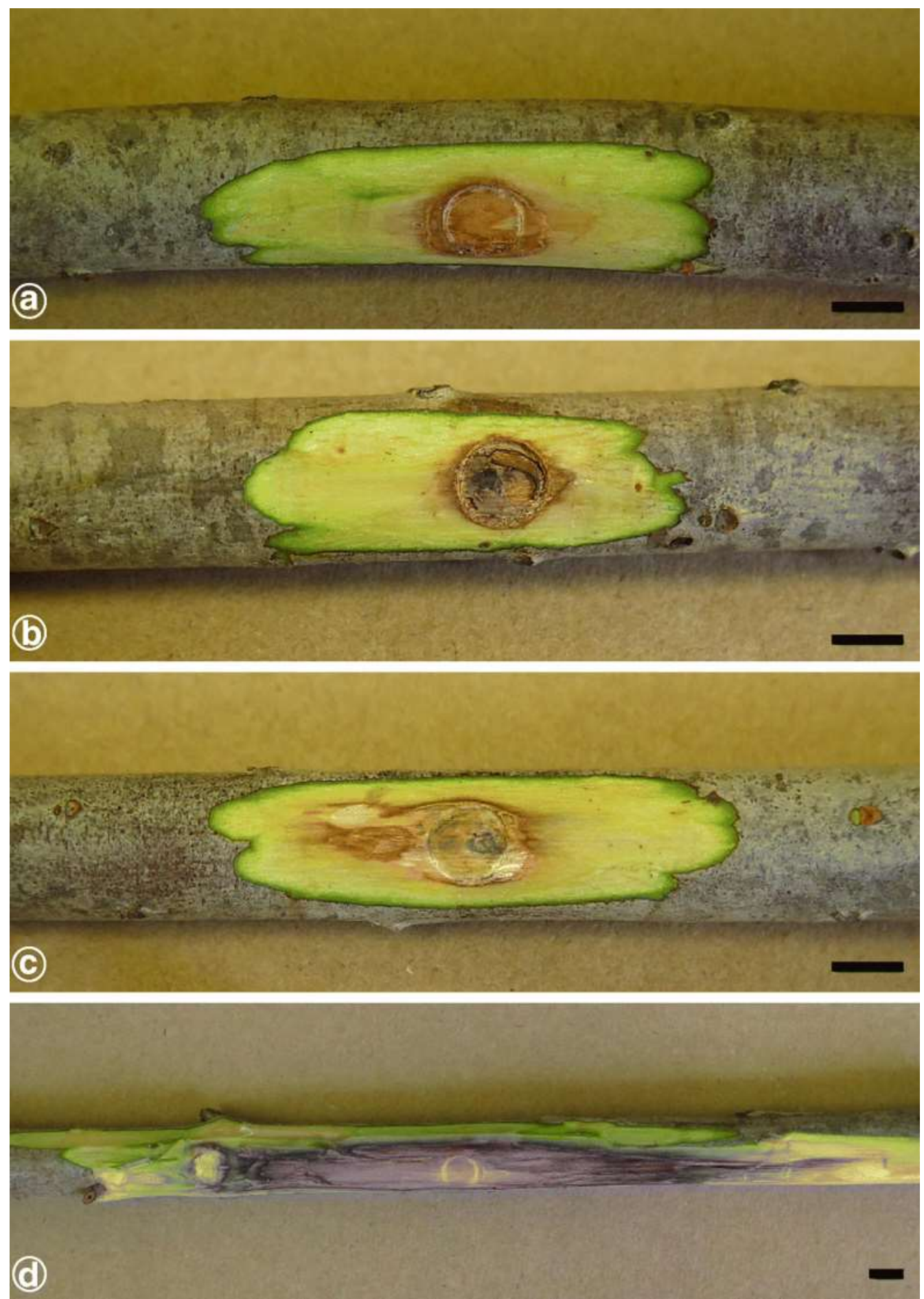

Figure 6. Produced lesions in the cambium of inoculated branches of Mimusops caffra within five weeks. A. Branches inoculated as a control with no evidence of lesion development. B. Pseudofusicoccum africanum (CMW 48028). C. Neofusicoccum variabile (CMW 37739). D. Neofusicoccum mangroviorum (CMW 48031). Scale bar $=6 \mathrm{~mm}$. 
by the lesions associated with Pseudofusicoccum africanum $(\bar{X}=10.4 \mathrm{~mm})$ and of Neofusicoccum variabile $(\bar{X}=10.3 \mathrm{~mm})$ (Fig. 7). All three Botryosphaeriales species were consistently re-isolated from lesions and no Botryosphaeriales were isolated from the controls.

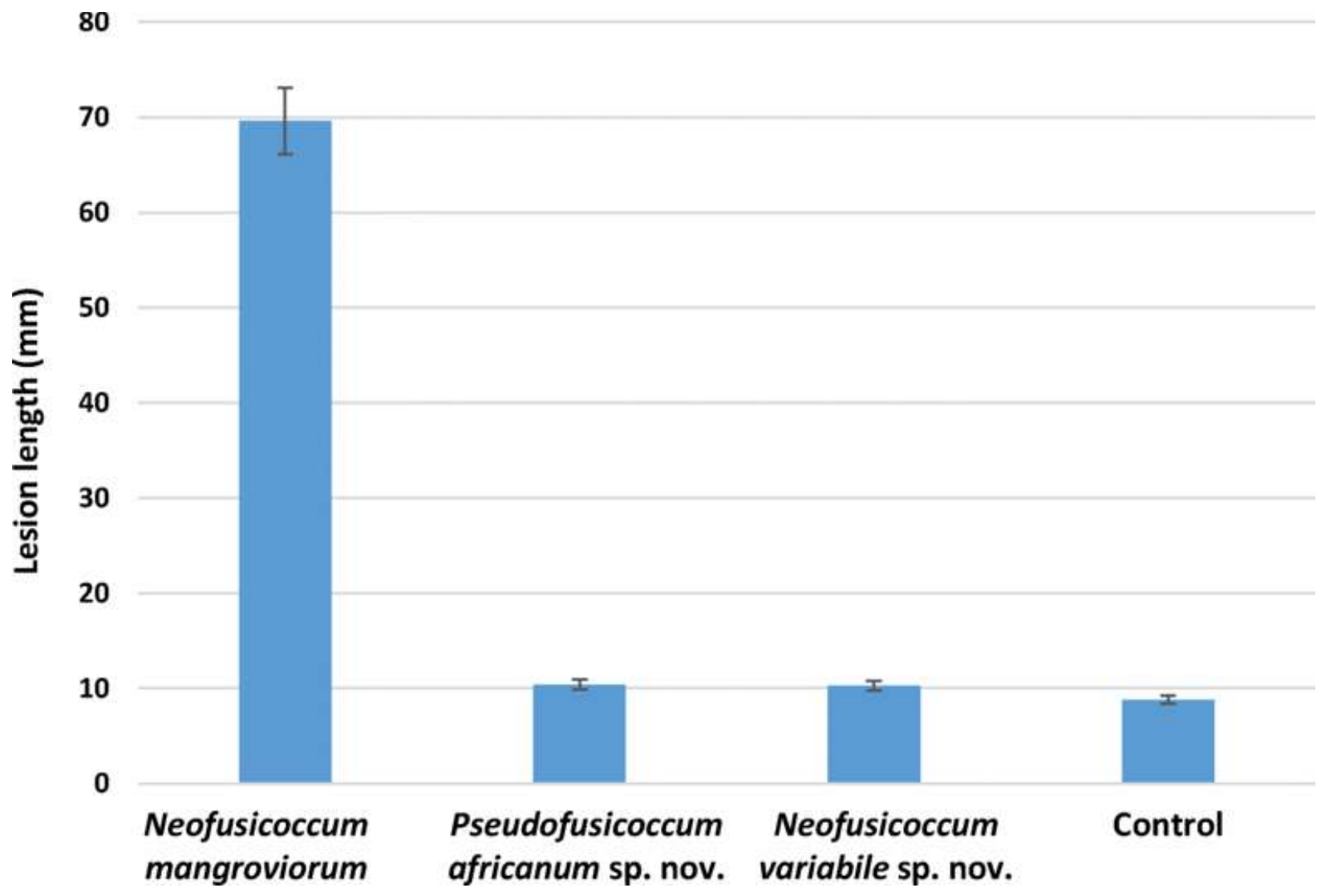

Figure 7. Mean lesion length (mm) for species of Botryosphaeriales five weeks after inoculation on Mimusops caffra.

\section{Discussion}

Three Botryosphaeriales species were identified associated with die-back symptoms on Mimusops caffra in South Africa. These included the known species Neofusicoccum mangroviorum and two new species described here as $N$. variabile and Pseudofusicoccum africanum. This is the first 
record of Botryosphaeriales from $M$. caffra and it appears that $N$. mangroviorum is the most likely cause of the die-back commonly observed on these trees.

The species isolated in this study reside in the two families Botryosphaeriaceae and Pseudofusicoccumaceae. Botryosphaeriaceae Theiss. \& Syd. (1918) represents the most diverse family in Botryosphaeriales, including 23 genera (Slippers et al. 2017) and more than 190 species (Phillips et al. 2013; Slippers et al. 2017). In contrast, Pseudofusicoccumaceae Tao Yang \& Crous (2017) includes only the single genus Pseudofusicoccum (Mohali et al. 2006; Slippers et al. 2017) that accommodates eight species.

Neofusicoccum mangroviorum was first isolated from four mangrove species (Avicennia marina, Bruguiera gymnorrhiza, Lumnitzera racemosa and Rhizophora mucronata) in a coastal region of South Africa by Osorio et al. (2017). This fungus has been isolated from both symptomatic and asymptomatic tissues of native trees in a previous (Osorio et al. 2017) and the current study. Interestingly all isolates of this fungus have been found on trees in coastal areas in close proximity to each other in South Africa. This suggests that N. mangroviorum could be native to South Africa, but more in depth studies would be needed to resolve this question.

Neofusicoccum mangroviorum was the only species in this study that produced significantly long lesions in the pathogenicity trials. This fungus was collected from die-back symptoms and it appears to be the most likely cause of those symptoms. Neofusicoccum mangroviorum was previously isolated from asymptomatic mangrove trees in South Africa, but was shown to be highly aggressive on mangrove (B. gymnorrhiza) in an inoculation trial (Osorio et al. 2017). The die-back symptoms on $M$. caffra in this study were common on trees, but they did not appear to 
result in serious disease. This most likely relates to the fact that these fungi are typically stressassociated and opportunistic pathogens (Mehl et al. 2013; Slippers and Wingfield, 2007).

Based on phylogenetic inference, the new species of Neofusicoccum described in this species resides in a sister clade with $N$. lumnitzerae. Neofusicoccum variabile is distinct from $N$. lumnitzerae in its morphology, most specifically in the shape of the conidia and the presence of spermatia. Neofusicoccum lumnitzerae was first isolated from L. racemosa in a coastal region in South Africa (Osorio et al. 2017) and it was interesting to find a closely related species from a very similar ecological niche in the present study.

Pseudofusicoccum africanum described here resides in a genus that was first reported from the branches of Eucalyptus urophylla and Acacia mangium in Venezuela (Mohali et al. 2006). Other species have subsequently been described from various unrelated trees in Venezuela, Australia, South Africa and Thailand (Pavlic et al. 2008; Mehl et al. 2011; Trakunyingcharoen et al. 2015). The discovery of a new species of Pseudofusicoccum in this study adds credence to the fact that this is a widely distributed genus that is still poorly sampled globally.

Four species of Botryosphaeriales have previously been collected in the general area where $M$. caffra was sampled in the present study. These include Lasiodiplodia gonubiensis and N. australe from Vachellia (=Acacia) karroo (Jami et al. 2015), Phyllosticta carissicola on Carissa macrocarpa (Crous et al. 2015) and Umthunziomyces hagahagensis on M. caffra leaves (Crous et al. 2017). Interestingly, there was no overlap between those taxa and the species that emerged from this study. These results might suggest some level of host specificity although most of these fungi tend to have relatively wide host ranges (Slippers et al. 2017). Clearly an extensive sampling including many woody species in the area would be required to resolve this question. 
Discovery of two new taxa in this limited study suggests that the Botryosphaeriales remains relatively incompletely sampled in South Africa. And this is likely true for many other parts of the world. The species isolated in this study do not appear to be causing a serious disease problem and they are most likely native to the relatively undisturbed sampling area. Yet an important and emerging issue relating to the Botryosphaeriales is that they can be easily moved to new areas in asymptomatic plant tissue (Crous et al. 2016; Marsberg et al. 2017; Slippers et al. 2017). In this regard, there are growing examples where these and other fungi that live as endophytes in healthy plant tissue, become important pathogens in areas where they are accidentally introduced (Burgess and Wingfield, 2017). This provides strong motivation to collect and document the diversity and distribution of the Botryosphaeriales globally and thus to better understand their relevance as plant pathogens.

\section{Acknowledgments}

We thank Prof. Brenda Wingfield for assistance in collecting samples and in conducting the pathogenicity tests. Members of the Tree Protection Cooperative Programme (TPCP), the DST/NRF Centre of Excellence in Tree Health Biotechnology (CTHB) and the University of Pretoria, South Africa, are acknowledged for financial support.

\section{References}

Burgess TI, Wingfield MJ (2017). Pathogens on the Move: A 100-Year Global Experiment with Planted Eucalypts. BioScience 67: 14-25.

Carbone I, Kohn LM (1999). A method for designing primer sets for speciation studies in filamentous ascomycetes. Mycologia 91: 553-556. 
Crous PW, Wingfield MJ, Le Roux J, et al. (2015). Fungal Planet description sheets: 371-399. Persoonia 35: 264-327.

Crous PW, Groenewald JZ, Slippers B, et al. (2016). Global food and fibre security threatened by current inefficiencies in fungal identification. Phil. Trans. R. Soc. B 371: 20160024.

Crous PW, Wingfield MJ, Burgess TI, et al. (2017). Fungal Planet description sheets: 469-557. Persoonia 37: 218 .

Desprez-Loustau ML, Marçais B, Nageleisen LM, et al. (2006). Interactive effects of drought and pathogens in forest trees. Ann For Sci 63: 597-612.

Gardes M, Bruns TD (1993). ITS primers with enhanced specificity for basidiomycetes application to the identification of mycorrhizae and rusts. Mol Ecol 2: 113-118.

Glass NL, Donaldson GC (1995). Development of primer sets designed for use with the PCR to amplify conserved genes from filamentous ascomycetes. Appl Environ Microb 61: 1323-1330.

Jami F, Slippers B, Wingfield MJ, et al. (2012). Five new species of the Botryosphaeriaceae from Acacia karroo in South Africa. Cryptogamie, Mycol 33: 245-266.

Jami F, Slippers B, Wingfield MJ, et al. (2015). Temporal and spatial variation of Botryosphaeriaceae associated with Acacia karroo in South Africa. Fungal Ecol 15: 51-62.

Jami F, Wingfield MJ, Gryzenhout M, et al. (2017). Diversity of tree-infecting Botryosphaeriales on native and non-native trees in South Africa and Namibia. Australas Plant Path DOI 10.1007/s13313-017-0516-x.

Marsberg A, Kemler M, Jami F, et al., 2017. Botryosphaeria dothidea: a latent pathogen of global importance to woody plant health. Mol Plant Pathol 18: 477-488. 
Mehl JWM, Slippers B, Roux J, et al. (2011). Botryosphaeriaceae associated with Pterocarpus angolensis (kiaat) in South Africa. Mycologia 103: 534-553.

Mehl JWM, Slippers B, Roux J, et al. (2013). Cankers and other diseases caused by the Botryosphaeriaceae. In: Gonthier P, Nicolotti G (eds), Infectious Forest Diseases. CAB International, Oxon, UK, pp. 298-317.

Mohali S, Slippers B, Wingfield MJ (2006). Two new Fusicoccum species from Acacia and Eucalyptus in Venezuela, based on morphology and DNA sequence data. Mycol Res 110: 405-413.

Osorio JA, Crous CJ, De Beer ZW, et al. (2017). Endophytic Botryosphaeriaceae, including five new species, associated with mangrove trees in South Africa. Fungal Biol 121: 361-393.

Pavlic D, Wingfield MJ, Barber P, et al. (2008). Seven new species of the Botryosphaeriaceae from baobab and other native trees in Western Australia. Mycologia 100: 851-866.

Phillips AJL, Alves A, Abdollahzadeh J, et al. (2013). The Botryosphaeriaceae: genera and species known from culture. Stud Mycol 76: 51-167.

Posada D, Buckley TR (2004). Model selection and model averaging in phylogenetics: advantages of Akaike information criterion and Bayesian approaches over likelihood ratio tests. Systematic Biol 53: 793808.

Rayner RW (1970). A mycological colour chart. Commonwealth Mycological Institute and British Mycological Society, Kew, Surrey, UK.

Slippers B, Crous PW, Jami F, et al. (2017). Diversity in the Botryosphaeriales: Looking back, looking forward. Fungal Biol 121: 307-321.

Slippers B, Wingfield MJ (2007). Botryosphaeriaceae as endophytes and latent pathogens of woody plants: diversity, ecology and impact. Fungal Biol Rev 21: 90-106. 
Sturrock R, Frankel S, Brown A, et al. (2011). Climate change and forest diseases. Plant Pathol 60: 133149.

Theissen F, Sydow H (1918). Vorentwürfe zu den Pseudosphaeriales. Annales Mycologici 16: 1-34.

Trakunyingcharoen T, Lombard L, Groenewald JZ, et al. (2015). Caulicolous Botryosphaeriales from Thailand. Persoonia 34: 87-99.

White TJ, Bruns T, Lee S, et al. (1990). Amplification and direct sequencing of fungal ribosomal RNA genes for phylogenetics. PCR protocols: a guide to methods and applications. Eds., MA Innis, DH Gelfand, JJ Sninsky, and TJ White. Academic Press, New York: 315-322.

Yang T, Groenewald JZ, Cheewangkoon R, et al. (2017). Families, genera and species of Botryosphaeriales. Fungal Biol 121: 322-346. 